\title{
Econocomics: Teaching Translation of Economic and Financial Texts through Comics
}

Comics have commonly be seen as a popular genre, having the main purpose of entertaining people. Recent research has shown that comic books and graphic novels can also deal with serious topics and, as a consequence, be used for educational purposes (Babic 2013). This paper describes the results of a study focusing on the use of comic books for the didactics of economic (Goodwin 2012) and of economic translation, in a classroom of MA students in specialized translation. It shows how the translation of comics dealing with economic and financial topics can be a hard task for university students in specialized translation. As a matter of fact, the blending of different registers, the informal one in the characters' balloons and the formal one in the narrative frames, as well as the interaction of words and images, may cause significant troubles to students as comics entail different translation strategies (Zanettin 2008) as well as intercultural competences. The paper illustrates the results of two case studies. The first one focuses on some parallel texts, including samples from the English source text and their Italian translations, and comments on the decisions made by professionals in order to manage translation problems. The second case study describes the problems encountered by a group of MA students in specialized translation, who were asked to translate, from American English to Italian, a frame taken from The Economic Meltdown Funnies, a comic book co-published by Jobs with Justice and the Institute for Policy Studies' Program on Inequality and the Common Good. In both cases, the analysis was carried out using a methodology inspired to the contributions from visual grammar (Kress and Leeuwen 2006), cognitive linguistics (Evans and Green 2006) and functionalist approaches to translation (Nord 2007). 